Discussion Paper No. 05-78

\title{
Is a Newspaper's Companion Website a Competing Outlet Channel for the Print Version?
}

Ulrich Kaiser

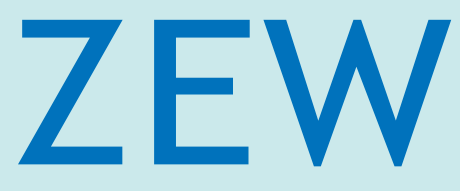

Zentrum für Europäische Wirtschaftsforschung $\mathrm{GmbH}$

Centre for European

Economic Research 
Discussion Paper No. 05-78

\title{
Is a Newspaper's Companion Website a Competing Outlet Channel for the Print Version?
}

\author{
Ulrich Kaiser
}

Download this ZEW Discussion Paper from our ftp server:

\begin{abstract}
ftp://ftp.zew.de/pub/zew-docs/dp/dp0578.pdf
\end{abstract}
Die Discussion Papers dienen einer möglichst schnellen Verbreitung von neueren Forschungsarbeiten des ZEW. Die Beiträge liegen in alleiniger Verantwortung der Autoren und stellen nicht notwendigerweise die Meinung des ZEW dar.

Discussion Papers are intended to make results of ZEW research promptly available to other economists in order to encourage discussion and suggestions for revisions. The authors are solely responsible for the contents which do not necessarily represent the opinion of the ZEW. 


\section{Non-technical summary}

Participants in and observers of print media markets have widely divergent beliefs about the effect of print media companion websites on print circulation. Optimists point to the convenient and cost-effective way of subscribing on the Internet, the reach of a different audience over the Internet (that might be turned into purchasers of the print version), and additional services which can be offered over the Internet such as searchable archives, permanently updated news, chat-rooms, bulletin boards, instant messaging and links to external content. Pessimists believe that companion websites induce channel competition on the print version since print media are information products for which the threat of cannibalization is believed to be particularly imminent.

This paper econometrically tests for channel competition between newspapers and their companion websites using Granger non-causality tests and indeed finds statistically significant evidence for channel competition between print circulation and website visits for national newspapers, a result that is stable over the time period of consideration. While national newspapers appear to loose readers to their online companion, local newspapers increase their customer base due to the internet, at least in the period after I/2002. 


\title{
Is a Newspaper's Companion Website a Competing Outlet Channel for the Print Version?
}

\author{
ULRICH KAISER*
}

October 25, 2005

\begin{abstract}
This paper uses Granger non-causality tests to analyze if channel competition exists between the companion websites of 93 German newspapers observed between I/1998 and II/2005. It provides econometric evidence for significant negative effects of companion website traffic on the print circulation of national newspapers and for significantly positive effects on local newspapers, at least for the period since $\mathrm{I} / 2002$.
\end{abstract}

JEL-classification: C32, C33, L11

Keywords: channel competition, Granger non-causality, panel data models, website visits, magazine circulation

II gratefully acknowledge competent research assistance provided by Søren Mejlby Johansen.

${ }^{*}$ University of Southern Denmark at Odense, Dept. of Economic, Campusvej 55, 5230 Odense M, Denmark, email: uka@sam.sdu.dk, http://www.sam.sdu.dk/staff/uka; Centre for European Economic Research, Mannheim, Centre for Economic and Business Research, Copenhagen, and Centre for Industrial Economics at the University of Copenhagen. 


\section{Introduction}

Industry observers have widely divergent believes about the effects of newspaper companion websites on their own print circulation. The universe of opinions ranges from statements like "Newspapers are cannibalizing themselves." (Frederick W. Searby of J.P. Morgan in The New York Times) ${ }^{1}$ to more moderate claims by Barsh et al. (2001, p. 91) who argue that companion websites are "a necessary step in the effort of a magazine to broaden and deepen its audience", an idea that is also advocated in a recent Wall Street Journal article (Matlick, 2005).

Existing empirical studies have also produced a fairly wide array of results. Some authors, such as Deleersnyder et al. (2002) for British and Dutch newspapers and Gentzkow (2003) for the Washington Post, find little evidence of channel competition between companion websites and newspaper circulation. By contrast, Filistrucchi (2004) uses data for the five leading national Italian newspapers to show that there indeed are internet cannibalization effects, a result that is shared by Simon (2004) for US popular magazines. The paper by Pauwels and Dans (2001) suggests channel complementarity between internet companions and the print versions of Spanish newspapers. The authors do not, however, consider the possibility of reverse causality.

A major flaw of existing studies for the newspaper market is that they, with excep-

\footnotetext{
${ }^{1}$ Cited by Seelye (2005).
} 
tions of the now somewhat outdated - given the surge in internet penetration in recent years - contributions by Deleersnyder et al. (2002) and Pauwels and Dans (2001), do not account for the different degrees to which companion websites are accessed by consumers. This appears to be important since a website that generates no traffic will hardly induce channel competition on the print version. This paper therefore uses website visits data for a total of 93 German newspapers observed quarterly between I/1998 and II/2005. It uses Ganger non-causality (GnC) tests to assess whether or not traffic on the companion website is a substitute or a complement to print circulation.

Newspapers may be more prone to channel competition than magazines, the other print medium of potential interest, since they tend to be read for information while reading magazines is mainly hedonic so that reading magazine articles from a computer screen may be less enjoyable than reading them sitting on the sofa or in the bath tub. Germany is chosen as the country of interest since particularly accurate data on circulation and website visits is available. The data contains information on consists on all eight national newspapers and 85 local newspapers (or 22 per cent of all local newspapers). The German newspaper market is the fifth largest in the world, behind (in that order) China, India, Japan, and the United States (World Association of Newspapers, 2005).

The main result of this paper is that there is evidence for channel competition between companion websites and print circulation for national newspapers. For 
national newspapers there is also evidence for causalities running in the other direction since I find statistically significant and positive effects of print circulation on website visits. Print circulation of local newspapers appears on the contrary do benefit from companion websites since the estimation results indicate statistically significant positive effects running from website visits to print circulation. There is no evidence for effects running in the other direction.

\section{Data and Econometric Methodology}

\section{$2.1 \quad$ Data}

\section{Data sources and number of observations}

I use publicly available data on newspaper circulation and website visits from http://www.ivw-online.de. The data spans the period I/1998 to II/2005, or 30 quarters (periods). In this respect, the time series dimension of my data is fairly large. I regard the website visits information as reliable for two reasons: (i) magazines use this data to sell advertising space and (ii) it is collected by an impartial nonprofit public utility institution, the "Information Association for the Determination of the Spread of Advertising Media" ("Informationsgemeinschaft zur Feststellung der Verbreitung von Werbeträgern e.V.", IVW) — the German equivalent to the US Audit Bureau of Circulation. IVW ascertains, monitors and publishes circula- 
tion and magazine dissemination information with, according to IVW's statutes, the aim to facilitate open competition between the suppliers of advertising space. IVW also is the original source of the circulation data I use in this study. Suppliers of online advertising space may join IVW and, once their membership is approved, are endowed with the IVW's technical equipment for measuring website visits.

It is not surprising that many local newspaper websites are not tracked by the IVW data since they tend to contain little advertising. Thus, they do not need to gather visits data from a publisher's point of view. Therefore, I thus suspect my local newspaper data to contain just a fraction of all newspaper websites, although I lack consistent information on website presence of local newspapers from my local newspapers sample.

The companion websites in the sample attract on average 3,667,066 mio. website visits per quarter. This compares to an average quarterly print circulation of the newspapers of $12,312,980$.

A more thorough description of the data set and variable definitions can be found in Appendix A.

I adjust for seasonality in my time series by running newspaper-specific OLS regressions on a set of seasonal dummies and a linear trend. If statistically significant seasonality is found, the seasonal part is removed.

There is a break in the time series for website visits in $I / 2002$. This is due to a change in the technology used by IVW to measure the number of website visits. I 
account for the break in the empirical analysis below by including dummy variables at the known breakpoint and by re-running the regressions on the post-I/2002 data only.

None of the newspaper websites under consideration charges access fees and none do require registration.

\subsection{Methodology}

I apply the Granger (1969) non-causality (GnC) methodology to test for causalities between circulation and website visits. One variable, say, $x$, is Granger-causal for another, $y$, if - conditional on past values of $y$ - the inclusion of past values of $x$ significantly improves the predictability of $y$. I rely on this definition in order to identify the relationships between circulation and website visits from their covariations over time within a dynamic model. ${ }^{2}$

The basic empirical model is a bivariate vector autoregression (VAR) for the log of circulation, $c_{i t}$ and the log of visits to the companion website, $v_{i t}$, of magazine $i$ in periods $t=1,2, \ldots, T_{i}$. The VAR is a standard vehicle for $\mathrm{GnC}$ analysis, as it allows for shocks in both the real and the virtual markets to be correlated, and to have lagged effects within a particular market ("own-effects") as well as lagged "cross-effects" between markets.

\footnotetext{
${ }^{2}$ See Dekimpe and Hanssens (2000) for a recent overview of the use of time series techniques in the marketing literature, including the Granger causality concept.
} 
The magazine-specific model is formulated in terms of the approximate quarterly growth rates of circulation and website visits, $\Delta \boldsymbol{X}_{i t}=\left(\Delta c_{i t}, \Delta v_{i t}\right)^{\prime}$,

$$
\Delta \boldsymbol{X}_{i t}=\boldsymbol{\Gamma} \Delta \boldsymbol{X}_{i t-1}+\theta_{0} D_{i t}+\theta_{1} D_{i t-1}+\mu_{i}+\epsilon_{i t}, \quad t=1,2, \ldots, T_{i}, \quad i=1,2, \ldots, N,
$$

where $\mu_{i}=\left(\mu_{c i}, \mu_{v i}\right)^{\prime}$ denotes a vector of drift parameters. Estimation in first differences is consistent with standard panel unit root tests and graphical analyzes of the variables under consideration. The subscripts $c$ and $v$ denote drift parameters for circulation and website visits respectively. They translate to linear time trends in a levels model. The pooled OLS model that I apply in order to estimate Equation (1) assumes that the drift parameters $\mu_{i}$ all collapse into a single constant term while the alternative model I apply, the fixed effects model, allows for newspaper-specific drift terms. The error term $\epsilon_{i t}$ is assumed to be independently and identically distributed across $i$ and $t$, with mean zero and a variance matrix $\Omega .^{3}$

The parameters of main interest for the $\mathrm{GnC}$ analysis are contained in the matrix

$$
\boldsymbol{\Gamma}=\left(\begin{array}{ll}
\gamma_{11} & \gamma_{12} \\
\gamma_{21} & \gamma_{22}
\end{array}\right)
$$

The Granger non-causality ( $\mathrm{GnC}$ ) hypotheses are: as follows:

$H_{v}: \gamma_{12}=0$ is the hypothesis of Granger non-causality from website visits to circulation and

\footnotetext{
${ }^{3}$ I apply covariance estimates that are robust to heteroscedasticity throughout. The assumption of $\epsilon_{i t}$ being independent across magazines is commonplace in panel data analysis.
} 
$H_{c}: \gamma_{21}=0$ is the hypothesis of Granger non-causality from circulation to website visits.

The remaining terms in Equation (1) take account of instantaneous and lagged effects of the change in the website measurement technology in 2002/I via the term $D_{i t}$ (an impulse dummy that takes the value one in 2002/I and zero elsewhere) and its lagged value, $D_{i t-1}$.

\section{Results}

Table 1 presents the results of the $\mathrm{GnC}$ tests. The upper panel of Table 1 shows the results for all newspapers without differentiation between national and local ones. None of the cross - coefficients is statistically significantly different from zero. There is hence neither evidence for channel competition nor evidence for channel complementarity for the German newspaper market as a whole.

\section{Insert Table 1 about here!}

It may be the case, however, that the patterns of causality are different for national newspapers and local newspapers. Consumers may for example subscribe to a local newspaper and read it at the breakfast table or on their way to work and look up national and international news with in-depth commentary on the internet. At the 
same time, local newspapers may want to use the internet companion to feature national and international news by for example posting press agency releases. The middle panel of Table 1 therefore presents separate estimation results for national newspapers while the lower panel displays the results for local newspapers.

The GnC tests provide weak statistical evidence for the presence of Granger causality running from circulation to website visits for the segment of national newspapers. An increase in circulation by one per cent leads to an increase in website visits by 0.6399 per cent in the pooled OLS model and by 0.6651 per cent in the more flexible model with fixed effects (joint statistical significance of the fixed effects is rejected by the data, however). Circulation hence is a channel complement to website visits. Quite the opposite is true for the inverse relationship: there are statistically highly significant negative effects of website visits on print circulation in the fixed effects model, thus indicating channel competition between the two media. The effect is quantitatively small, however. The fixed effects (the newspaper-specific drift parameters) are also statistically highly significant which is why this model should be preferred over the pooled OLS model. A one percent increase in website visits leads to a decrease in circulation by 0.022 per cent. Given average growth rates of website visits of 7.1 per cent in 2005 and 6.4 per cent over the entire period, this effect might clearly not be as negligible as it seems at first sight.

While there indeed are statistically significant causalities between website visits and circulation for national newspapers, no such relationships exist for local newspapers, 
even though the corresponding $\mathrm{GnC}$ tests are rejected at the twelve percent marginal significance level only. The coefficient estimates indicate a positive relationship between website visits and circulation which might imply, given the negative link for national newspapers, why the estimation results for the entire market are statistically insignificant.

It is certainly possible that including impulse dummies in the regressions does not fully capture the effects of the change in website traffic recording in I/2002. Likewise, my parameter estimates may not be constant across time, an issue that appears important before the background of continuously increasing internet penetration rates. Table 2 therefore displays estimation results for a restricted sample of observations including and past quarter I/2002. The from a practitioner's point of view possibly most interesting result of channel competition between website visits and circulation for national newspapers persist. The causal effect of a one per cent increase in website visits on circulation is now estimated to be 0.0308 per cent. This change relative to the coefficient estimate for the entire time period could be caused by the change in measurement technology or by companion websites having become stronger competitors for the print version, possibly due to an increased internet affluence of readers.

Interestingly, the positive but imprecisely measured effects of website visits on print circulation for local newspapers persists. In the more recent time period this effect 
also is statistically weakly significant. The point estimates indicate an increase in print circulation of around 0.004 per cent due to an increase in website visits of one per cent.

Insert Table 2 about here!

For completeness, Appendix B displays estimation results for the period prior to I/2002. It shows that there are no statistically significant relationships between website visits and circulation in the early time period. The lack of significance might simply be due to the fact that sample sizes decreased by between 73.4 per cent (all newspapers) and 56.6 per cent (national newspapers). The result of statistical insignificance might, however, also be due to substantially lower internet penetration rates in the period prior to 2002 compared to today. This in turn might help explaining why the earlier study by Deleersnyder et al. (2002) did not find economically sizeable effects of website presence on print circulation.

\section{Conclusion}

Participants in and observers of print media markets have widely divergent beliefs about the effect of print media companion websites on print circulation. Optimists point to the convenient and cost-effective way of subscribing on the Internet, the 
reach of a different audience over the Internet (that might be turned into purchasers of the print version), and additional services which can be offered over the Internet such as searchable archives, permanently updated news, chat-rooms, bulletin boards, instant messaging and links to external content. Pessimists believe that companion websites induce channel competition on the print version since print media are information products for which the threat of cannibalization is believed to be particularly imminent (Shapiro and Varian, 1999).

This paper econometrically tests for channel competition between newspapers and their companion websites using Granger non-causality tests. It uses quarterly data for 93 German newspapers observed between I/1998 and II/2005. It indeed finds statistically significant evidence for channel competition between print circulation and website visits for national newspapers, a result that is stable over the time period of consideration. The point estimates suggest a decrease in circulation by around 0.0308 per cent due to an increase in website visits by one percent. This number has to be interpreted in the light of average quarterly growth rates in website visits by 6.4 per cent per quarter. While national newspapers appear to loose readers to their online companion, local newspapers increase their customer base due to the internet, at least in the period after I/2002. The results indicate that a one percent change in website visits leads to a 0.0039 percent increase in print circulation. This differential effect for national and local newspapers might be due to local newspapers using the internet to increase their coverage of national and international 
news, thereby complementing their print version. At the same time readers of local newspapers may also click through to the websites of national newspapers for in-depth coverage of national and international news, thereby avoiding the need to purchase the corresponding newspaper print version. Readers of national newspapers may also be more interested in information as such and do to a lesser extent extract utility from purchasing a print version rather than to call up information on the internet. These are, however, hypotheses the present paper cannot test. It still seems that there are different consumption patterns for national and local newspapers, an issue that could be worth discussing in future research. 
Table 1: Tests of Granger non-causality: circulation and website visits; results for the period I/1998 - II/2005

\begin{tabular}{|c|c|c|c|c|}
\hline & \multicolumn{2}{|c|}{ Pooled OLS } & \multicolumn{2}{|c|}{ Fixed effects } \\
\hline & Circ. & Visits & Circ. & Visits \\
\hline & $\Delta c_{i t}$ & $\Delta v_{i t}$ & $\Delta c_{i t}$ & $\Delta v_{i t}$ \\
\hline \multicolumn{5}{|l|}{ All newspapers } \\
\hline \multirow[t]{2}{*}{$\Delta c_{i t-1}$} & -0.0038 & 0.3521 & $-0.0893^{* * *}$ & 0.3463 \\
\hline & $(0.0334)$ & $(0.2496)$ & $(0.0198)$ & $(0.2613)$ \\
\hline \multirow[t]{2}{*}{$\Delta v_{i t-1}$} & 0.0015 & -0.0557 & 0.0007 & $-0.1230^{* *}$ \\
\hline & $(0.0020)$ & $(0.0410)$ & $(0.0021)$ & $(0.0281)$ \\
\hline GnC Hypothesis & $H_{v}$ & $H_{v}$ & $H_{v}$ & $H_{c}$ \\
\hline$(p-$ value $)$ & 0.4689 & 0.1586 & 0.7319 & 0.1853 \\
\hline$p$-value test of FE & - & - & 0.0000 & 0.1913 \\
\hline \multicolumn{5}{|c|}{ National newspapers } \\
\hline \multirow[t]{2}{*}{$\Delta c_{i t-1}$} & -0.0172 & $0.6399 *$ & $-0.1434^{* * *}$ & $0.6651 *$ \\
\hline & $(0.0683)$ & $(0.3694)$ & $(0.0521)$ & $(0.3617)$ \\
\hline \multirow[t]{2}{*}{$\Delta v_{i t-1}$} & -0.0157 & $-0.3320 * * *$ & $-0.0220 * *$ & $-0.3669^{* *}$ \\
\hline & $(0.0106)$ & $(0.0958)$ & $(0.0104)$ & $(0.0721)$ \\
\hline GnC Hypothesis & $H_{v}$ & $H_{v}$ & $H_{v}$ & $H_{c}$ \\
\hline$(p-$ value $)$ & 0.1394 & 0.0851 & 0.0358 & 0.0678 \\
\hline$p$-value test of FE & - & - & 0.0000 & 0.3228 \\
\hline \multicolumn{5}{|l|}{ Local newspapers } \\
\hline \multirow[t]{2}{*}{$\Delta c_{i t-1}$} & -0.0107 & 0.1382 & $-0.0807^{* * *}$ & 0.1341 \\
\hline & $(0.0345)$ & $(0.3020)$ & $(0.0217)$ & $(0.3257)$ \\
\hline \multirow[t]{2}{*}{$\Delta v_{i t-1}$} & 0.0033 & -0.0283 & 0.0031 & $-0.0978^{* *}$ \\
\hline & $(0.0020)$ & $(0.0424)$ & $(0.0020)$ & $(0.0303)$ \\
\hline GnC Hypothesis & $H_{v}$ & $H_{v}$ & $H_{v}$ & $H_{c}$ \\
\hline$(p-$ value $)$ & 0.1119 & 0.6472 & 0.1222 & 0.6807 \\
\hline$p$-value test of $\mathrm{FE}$ & - & - & 0.0000 & 0.2543 \\
\hline
\end{tabular}

Note: Table 1 displays the results of Granger non-causality $(\mathrm{GnC})$ tests between website visits and circulation. "Circ." is the equation for the quarterly circulation of a newspaper. "Visits" is the equation for the number of website visits to the companion website. Numbers in italics are the cross-effects of interest. Two different estimation approaches are used: pooled OLS and fixed effects estimation that includes a newspaper-specific intercept term. The tests are conducted separately for all newspapers (93 newspapers, 1,324 observations), national newspapers (8 newspapers, 171 observations) and local newspapers (85 newspapers, 1,153 observations). The numbers in parentheses are robust standard errors. The " $p$ test for FE" is the marginal significance level at which the presence of fixed effects cannot be rejected. The regressions include a constant term, impulse dummies for I/2002 and II/2002 (not shown in the table). The asterisks "***", "**" and "*" denote significance at the one, five and ten per cent level, respectively. The Granger noncausality $(\mathrm{GnC})$ tests refer to tests for causality running from website visits to advertising $\left(H_{v}\right)$ and to tests for causality running from advertising to website visits $\left(H_{a}\right)$. All specifications are statistically highly significant.

Reading example for the pooled OLS estimation of the circulation equation for all newspapers: a one per cent increase in circulation in the previous time period leads to a 0.0038 per cent decrease in circulation in the present period (standard error 0.0334 per cent); a one per cent increase in website visits in the previous time period leads to a 0.0015 per cent increase in circulation in the present period (standard error 0.0020 per cent). 
Table 2: Tests of Granger non-causality: circulation and website visits; results for the period I/2002 - II/2005

\begin{tabular}{|c|c|c|c|c|}
\hline & \multicolumn{2}{|c|}{ Pooled OLS } & \multicolumn{2}{|c|}{ Fixed effects } \\
\hline & Circ. & Visits & Circ. & Visits \\
\hline & $\Delta c_{i t}$ & $\Delta v_{i t}$ & $\Delta c_{i t}$ & $\Delta v_{i t}$ \\
\hline \multicolumn{5}{|l|}{ All newspapers } \\
\hline \multirow[t]{2}{*}{$\Delta c_{i t-1}$} & -0.0396 & $0.4598 *$ & $-0.1589 * * *$ & 0.3911 \\
\hline & $(0.0362)$ & $(0.2774)$ & $(0.0232)$ & $(0.3320)$ \\
\hline \multirow[t]{2}{*}{$\Delta v_{i t-1}$} & 0.0023 & -0.0573 & 0.0015 & $-0.1372^{* *}$ \\
\hline & $(0.0024)$ & $(0.0480)$ & $(0.0023)$ & $(0.0334)$ \\
\hline GnC Hypothesis & $H_{v}$ & $H_{v}$ & $H_{v}$ & $H_{c}$ \\
\hline$(p-$ value $)$ & 0.3371 & 0.0978 & 0.5250 & 0.2391 \\
\hline$p$-value test of FE & - & - & 0.0000 & 0.5565 \\
\hline \multicolumn{5}{|c|}{ National newspapers } \\
\hline \multirow[t]{2}{*}{$\Delta c_{i t-1}$} & -0.0663 & 0.3707 & $-0.2299^{* * *}$ & 0.3438 \\
\hline & $(0.0856)$ & $(0.4614)$ & $(0.0693)$ & $(0.4694)$ \\
\hline \multirow[t]{2}{*}{$\Delta v_{i t-1}$} & -0.0191 & $-0.3301^{* *}$ & $-0.0308 * *$ & $-0.3559^{* *}$ \\
\hline & $(0.0188)$ & $(0.1583)$ & $(0.0148)$ & $(0.0950)$ \\
\hline GnC Hypothesis & $H_{v}$ & $H_{v}$ & $H_{v}$ & $H_{c}$ \\
\hline$(p-$ value $)$ & 0.3131 & 0.4238 & 0.0396 & 0.4659 \\
\hline$p$-value test of FE & - & - & 0.0000 & 0.6240 \\
\hline \multicolumn{5}{|l|}{ Local newspapers } \\
\hline \multirow[t]{2}{*}{$\Delta c_{i t-1}$} & -0.0346 & 0.2184 & $-0.1451^{* * *}$ & 0.0572 \\
\hline & $(0.0348)$ & $(0.2527)$ & $(0.0244)$ & $(0.3566)$ \\
\hline \multirow[t]{2}{*}{$\Delta v_{i t-1}$} & $0.0039 *$ & -0.0209 & $0.0038 *$ & $-0.0933^{* *}$ \\
\hline & $(0.0024)$ & $(0.0485)$ & $(0.0021)$ & $(0.0306)$ \\
\hline GnC Hypothesis & $H_{v}$ & $H_{v}$ & $H_{v}$ & $H_{c}$ \\
\hline$(p-$ value $)$ & 0.0989 & 0.3877 & 0.0767 & 0.8726 \\
\hline$p$-value test of $\mathrm{FE}$ & - & - & 0.0000 & 0.0207 \\
\hline
\end{tabular}

Note: Table 2 displays the results of Granger non-causality $(\mathrm{GnC})$ tests between website visits and circulation. "Circ." is the equation for the quarterly circulation of a newspaper. The data is restricted to the period including and after the change in website visits measurement in I/2002. "Visits" is the equation for the number of website visits to the companion website. Numbers in italics are the cross-effects of interest. Two different estimation approaches are used: pooled OLS and fixed effects estimation that includes a newspaper-specific intercept term. The tests are conducted separately for all newspapers (90 newspapers, 941 observations), national newspapers (8 newspapers, 96 observations) and local newspapers (82 newspapers, 797 observations). The numbers in parentheses are robust standard errors. The " $p$ test for FE" is the marginal significance level at which the presence of fixed effects cannot be rejected. The regressions include a constant term, impulse dummies for I/2002 and II/2002 as well as a dummy variable for the periods after I/2002 (not shown in the table). The asterisks "***", "**" and "**" denote significance at the one, five and ten per cent level, respectively. The Granger non-causality $(\mathrm{GnC})$ tests refer to tests for causality running from website visits to advertising $\left(H_{v}\right)$ and to tests for causality running from advertising to website visits $\left(H_{a}\right)$. All specifications are statistically highly significant.

Reading example for the pooled OLS estimation of the circulation equation for all newspapers: a one per cent increase in circulation in the previous time period leads to a 0.0396 per cent decrease in circulation in the present period (standard error 0.0362 per cent); a one per cent increase in website visits in the previous time period leads to a 0.0023 per cent increase in circulation in the present period (standard error 0.0024 per cent) 14 


\section{Appendix A: Data and definitions}

\section{Data}

The econometric analysis combines two data sets: (i) data on website visits and (ii) data on magazine circulation as well as advertising pages. Both data sets are collected by the same institution, the "Information Association for the Determination of the Spread of Advertising Media" ("Informationsgemeinschaft zur Feststellung der Verbreitung von Werbeträgern e.V.", IVW) and can be downloaded free of charge from the Internet at http://www.ivwonline.de and http://medialine.focus.de. IVW ascertains, monitors and publishes circulation and magazine dissemination information as well as website visits. Magazines freely choose to join IVW to be able to provide potential advertisers with reliable figures on circulation and website visits. The IVW fees which need to be paid for the collection of circulation data range between 309 Euros (for magazines with a circulation of less than 5,000 copies in the last quarter of the respective earlier year) and 8,895 Euros (for magazines with a circulation of more than 5,000,000 copies). The fees which need to be paid for the collection of website visits data depend on the average number of website visits and range between 300 Euros and 1,200 Euros.

\section{Definitions}

Total circulation is measured as the residual between the number of newspaper copies produced and the number of newspapers returned to the publisher. A specific feature of the German magazine market is that publishers are obliged to pertaining unsold copies from distributors. There is a possibility of cheating on behalf of the publisher here, and cheating indeed has occurred in the German magazine market in the past (with severe reputation damages to the cheating magazines). IVW tries to ascertain the figures submitted by the publisher by drawing stratified random samples at newsstands and by extrapolating actual circulation based on this data. A "page visit" is defined as a successful and non-interrupted contact between an Internet browser and the magazine website from another URL. "Non-interrupted" means that, if a website is accessed once and the user continues to surf on the same website by clicking on different contents, this still is counted as a single access.

There is, however, a measurement problem in our data, due to the fact that "unique users" cannot ultimately be circumscribed due to the strict German data secrecy law and since website providers do not ask users to identify themselves. Accessing the websites in our sample is free of charge, so unique users cannot be identified from payment information either.

The information on website visits is gathered from so-called "log-files", i.e. the protocol of all accessed documents and user data submitted to the Internet server. Apart from the unique user issue, there also is a second measurement problem: more 
than one user can be attached to a single IP address, for example since dynamic IP addresses are used, which consequently means that many user visits might go unnoticed in our data. The use of "firewalls" creates the same type of measurement problem, since it translates several internal IP addresses into a single IP address, which means that website accesses by multiple users behind the same firewall are counted as one access. An IP address is an identifier for a computer or device on a network.

Website visits are technically measured by analyzing "clickstreams". A clickstream is the continuum of one or more website visits. The IVW measurement method analyzes when a visit begins within a clickstream, thereby only considering website accesses from the outside. So-called "referer variables", which are transferred by the web browser to the server log file, are used here. The starting point for a new visit is if a user accesses the website from the outside.

Even though I do have data on the number of "page impressions" - i.e. the access of an Internet site - as an alternative indicator of website visits I abstain from using it since it also measures the appearance of frames as a page impression which implies that a single website with, say, ten frames would be counted as ten Page Impressions. 
Appendix B: Tests of Granger non-causality: circulation and website visits; data for I/1998 to IV/2001

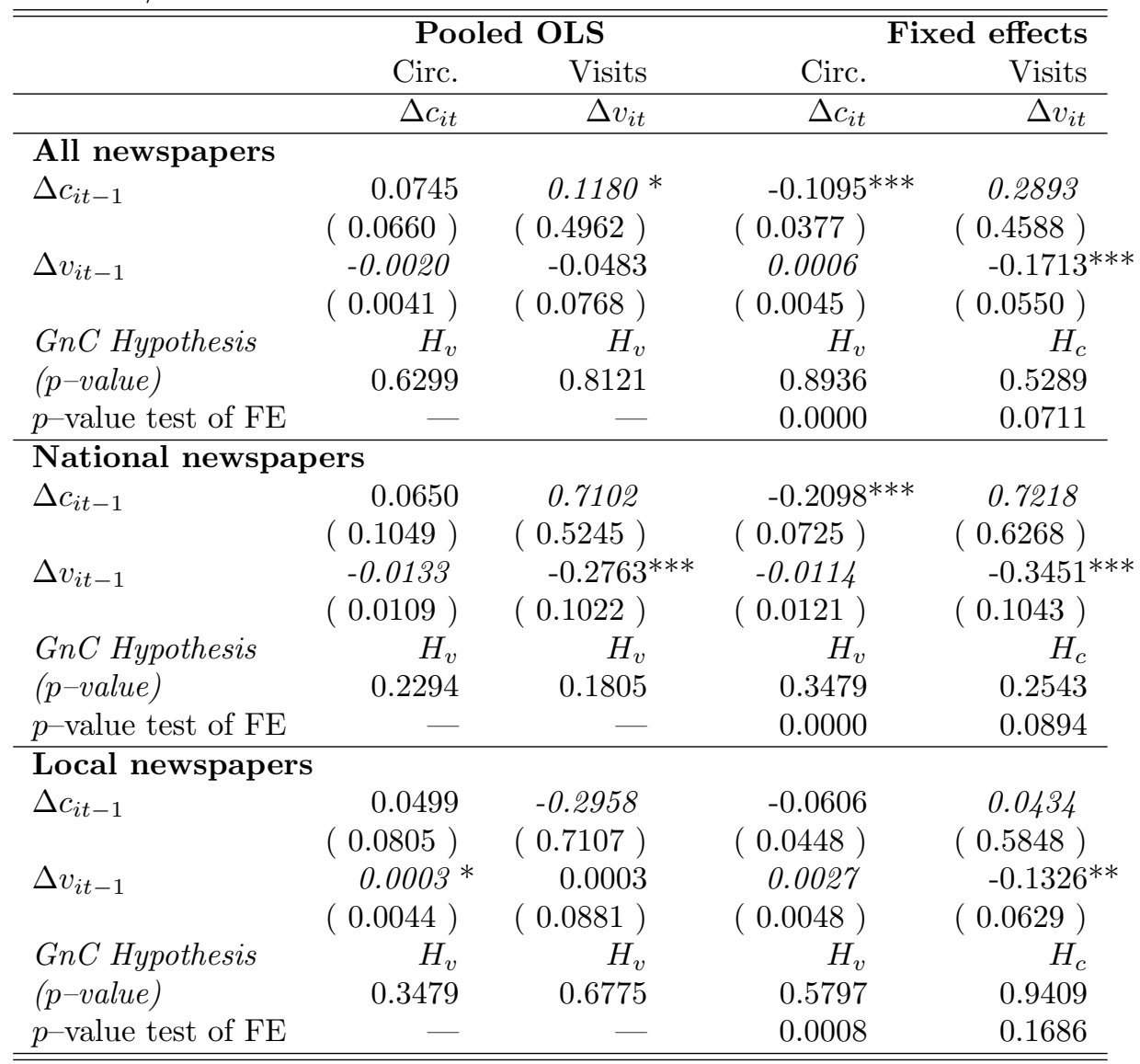

Note: Appendix displays the results of Granger non-causality ( $\mathrm{GnC}$ ) tests between website visits and circulation. "Circ." is the equation for the quarterly circulation of a newspaper. The data is restricted to the period including before the change in website visits measurement in I/2002. "Visits" is the equation for the number of website visits to the companion website. Numbers in italics are the cross-effects of interest. Two different estimation approaches are used: pooled OLS and fixed effects estimation that includes a newspaper-specific intercept term. The tests are conducted separately for all newspapers (51 newspapers, 383 observations), national newspapers (7 newspapers, 67 observations) and local newspapers (44 newspapers, 316 observations). The numbers in parentheses are robust standard errors. The " $p$ test for FE" is the marginal significance level at which the presence of fixed effects cannot be rejected. The regressions include a constant term. The asterisks "****, “**” and " **" denote significance at the one, five and ten per cent level, respectively. The Granger non-causality $(\mathrm{GnC})$ tests refer to tests for causality running from website visits to advertising $\left(H_{v}\right)$ and to tests for causality running from advertising to website visits $\left(H_{a}\right)$. All specifications are statistically highly significant.

Reading example for the pooled OLS estimation of the circulation equation for all newspapers: a one per cent increase in circulation in the previous time period leads to a 0.0745 per cent increase in circulation in the present period (standard error 0.0660 per cent); a one per cent increase in website visits in the previous time period leads to a 0.0020 per cent decrease in circulation in the present period (standard error 0.0041 per cent). 


\section{References:}

Barsh, J., E. Kramer, D. Maue, N. Zuckerman (2001), Magazines' home companion, The McKinsey Quarterly 2, 83-91.

Dekimpe, M. and D. Hanssens (2000), Time-series models in marketing: past, present and future, International Journal of Research in Marketing 17, 183193.

Deleersnyder, B., I. Geyskens, K. Gielens, and M. Dekimpe (2002), How cannibalistic is the Internet channel? A study of the newspaper industry in the United Kingdom and the Netherlands, International Journal of Research in Marketing 19, 337-348.

Gentzkow, M.A. (2003). Valuing new goods in a model with complementarities: online newspapers; Internet download: http://www.people.fas.harvard.edu/g̃entzkow/papers/PrintOnline.pdf.

Granger, C.W.J. (1969), Investigating causal relations by econometric models and cross-spectral methods, Econometrica 37, 424-438.

Filistrucchi, L. (2004), The impact of the internet on the market for daily newspapers in Italy, working paper, European University Institute; Internet download: http://www.uni-kiel.de/ifw/konfer/network2004/filistrucchi.pdf.

Matlick, J. (2005), Something Old, Something New: For new print magazines, an essential part of the start-up strategy is a smart Web site, The Wall Street Journal May 23, p. R8; Internet download: http://online.wsj.com/public/ article_print/0,,SB111627930855035062,00.html.

Pauwels, K. and E. Dans (2001), Internet marketing the news: leveraging brand equity from marketplace to marketspace, Brand Management 8(4), 303-314.

Seelye, K.Q. (2005), Can papers end the free ride online?, in : The New York Times March 14, 2005; Internet download:

http://www.nytimes.com/2005/03/14/business/

media/14paper.html?ex1111467600\&en=f82a8968e90f1331\&ei=5070.

Simon, D. (2004), The Effect of a magazine's digital content on its print circulation: cannibalization or complementarity?, Cornell University working paper.

World Association of Newspapers (2005), World Press Trends: Newspaper Circulation and Advertising Up Worldwide; Internet download: http://www.wanpress.org/article7321.html. 